\title{
Laryngopharyngeal Reflux: Weak Acid and Weaker Correlations
}

\author{
Steven R. DeMeester ${ }^{1}$ \\ Published online: 25 January 2019 \\ (c) Springer Science+Business Media, LLC, part of Springer Nature 2019
}

Cough, sore throat, hoarseness, globus sensation, neck pain, or a burning sensation in the tongue or mouth may be a consequence of laryngopharyngeal reflux (LRP), but these symptoms are non-specific and can be due to conditions other than LPR such as sinusitis, postnasal drip, allergies, or underlying laryngeal pathology $[1,2]$. Further, as the name implies, LPR is presumed to be related to reflux of gastric contents up to the larynx and pharynx. The challenge with LPR has been to objectively confirm the presence of the disease in those that have it and likewise exclude it in those with symptoms attributed to alternate etiologies. Currently, although there is no "gold standard" test for the diagnosis, objective testing options include impedance- $\mathrm{pH}$ monitoring, particularly with catheters that extend above the upper esophageal sphincter, dual-probe $\mathrm{pH}$ testing, and Restech ${ }^{\circledR}$ pharyngeal $\mathrm{pH}$ monitoring.

In this issue of Digestive Diseases and Sciences, Duricek and colleagues used simultaneous 24-h impedance-pH monitoring in both the distal esophagus and the pharynx to determine the presence of gastroesophageal reflux events and assess the proximal (pharyngeal) extent of these events [3]. They confirmed a weak but significant correlation between the number and duration of distal esophageal and proximal pharyngeal reflux events. Further, patients with pathologic distal esophageal acid exposure had significantly more reflux events and longer duration pharyngeal weak acid exposure compared to patients with normal distal esophageal acid exposure. In contrast, there was no association between pharyngeal reflux and the reflux symptom index (RSI) or reflux finding score (RFS) results. Likewise, there was no difference in RSI or RFS between patients with and without pathologic distal esophageal acid exposure. The authors concluded that there was no identifiable correlation

Steven R. DeMeester

sdemeester@orclinic.com

1 Division of Gastrointestinal and Minimally Invasive Surgery, The Oregon Clinic and The Foundation for Surgical Innovation and Education, 4805 NE Glisan Street, Suite 6N60, Portland, OR 97213, USA between pharyngeal reflux as determined by dual pharyngeal and distal esophageal 24-h impedance- $\mathrm{pH}$ monitoring and the symptoms and signs attributable to LPR as determined by RSI and RFS. It was their opinion that a direct, simple, quantitative relationship was unlikely to exist between pharyngeal reflux and the symptoms and signs attributed to LPR.

A strength of their study is the finding that pharyngeal reflux with refluxate of $\mathrm{pH}<4$ was rare and that most reflux events in the pharynx had a pH of 5.5-6.0. Consequently, similar to the Ryan score used to analyze data obtained with the Restech ${ }^{\circledR}$ pharyngeal $\mathrm{pH}$ probe, any assessment of pharyngeal reflux should not use the traditional $\mathrm{pH}$ cutoff of $<4$ that is used for distal esophageal $\mathrm{pH}$ monitoring [4]. Another strength was the significant correlation seen between distal esophageal reflux and pharyngeal reflux, reaffirming the concept that LPR likely originates as distal esophageal reflux events that are able to reach to the level of the larynx and pharynx. Since even infrequent episodes of reflux to the larynx can perpetuate symptoms, it is logical to assume that in these patients, some of their LPR symptoms may be attributable to proximal reflux events [5].

The challenge in studies such as this one is selecting the appropriate study population, since no "gold standard" exists for the diagnosis of LPR. The authors included only patients with LPR symptoms for $>6$ months, an $\mathrm{RSI}>13$ or an RFS $>7$ while not receiving antisecretory medications and at least one pharyngeal reflux episode as measured with dual impedance-pH monitoring. This approach was made under the assumption that the RSI and RFS would reliably identify patients with a high likelihood of having LPR based on objective studies, and is a weakness in the study design [6]. By enriching the study with subjects having high RSI and RFS scores, some of whom probably have LPR and others with an alternate etiology, the authors may have inadvertently weakened their ability to correlate symptoms with objective testing. This approach would be useful if LPR was the only possible etiology for the symptoms, but when multiple potential etiologies exist, the association between objective testing and LPR symptoms likely gets lost in the noise. 
Ultimately, confirmation that LPR symptoms are related to proximal reflux events will require demonstrating that elimination of all reflux events cures or improves symptoms. Although appealing, this is difficult to achieve in practice since proton pump inhibitors (PPIs) do not correct the pathophysiologic defects that allow reflux to occur, and numerous studies using impedance- $\mathrm{pH}$ confirm that while the $\mathrm{pH}$ of the refluxed material is changed by antisecretory medications, the number of reflux events is not significantly changed [7]. These weak acid reflux events are likely sufficient to perpetuate LPR symptoms in many patients despite PPI use [8]. Although an antireflux procedure is the only option that can reliably reduce or eliminate reflux events of all types, assessing the impact of the procedure on LPR symptoms is confounded by the slow improvement of chronic laryngeal symptoms combined with the placebo effect that can last for several months after the procedure [9].

Consequently, determining the etiology of the symptoms and developing a management strategy for patients with suspected LPR remain challenging. Studies such as this one highlight important concepts while also exposing areas where more work is needed. A thoughtful and objectively guided approach to the evaluation of patients suspected to have LPR is the starting point for efforts to improve the quality-of-life in this complex group of patients.

\section{Compliance with ethical standards}

Conflict of interest The authors declare that they have no conflict of interest.

\section{References}

1. Patel D, Vaezi M. Normal esophageal physiology and laryngopharyngeal reflux. Otolaryngol Clin North Am. 2013;46:1023-1041.

2. Rafii B, Taliercio S, Achlatis S, Ruiz R, Amin MR, Branski RC. Incidence of underlying laryngeal pathology in patients initially diagnosed with laryngopharyngeal reflux. Laryngoscope. 2014;124:1420-1424.

3. Duricek M. Acidic pharyngeal reflux does not correlate with symptoms and laryngeal injury attributed to laryngopharyngeal reflux. Dig Dis Sci. (Epub ahead of print). https://doi.org/10.1007/ s10620-018-5372-1.

4. Ayazi S, Lipham JC, Hagen JA, et al. A new technique for measurement of pharyngeal $\mathrm{pH}$ : normal values and discriminating $\mathrm{pH}$ threshold. J Gastrointest Surg. 2009;13:1422-1429.

5. Morice AH. Is reflux cough due to gastroesophageal reflux disease or laryngopharyngeal reflux? Lung. 2008;186:103-106.

6. Friedman M, Hamilton C, Samuelson CG, et al. The value of routine $\mathrm{pH}$ monitoring in the diagnosis and treatment of laryngopharyngeal reflux. Otolaryngol Head Neck Surg. 2012;146:952-958.

7. Hemmink GJ, Bredenoord AJ, Weusten BL, Monkelbaan JF, Timmer R, Smout AJ. Esophageal $\mathrm{pH}$-impedance monitoring in patients with therapy-resistant reflux symptoms: "on" or "off" proton pump inhibitor? Am J Gastroenterol. 2008;103:2446-2453.

8. Tutuian R, Mainie I, Agrawal A, Adams D, Castell DO. Nonacid reflux in patients with chronic cough on acid-suppressive therapy. Chest. 2006;130(2):386-391.

9. Worrell SG, DeMeester SR, Greene CL, Oh DS, Hagen JA. Pharyngeal $\mathrm{pH}$ monitoring better predicts a successful outcome for extraesophageal reflux symptoms after antireflux surgery. Surg Endosc. 2013;27(11):4113-4118. 